\title{
Strengths-based leadership and its impact on task performance: A preliminary study
}

\begin{tabular}{|c|c|}
\hline \multicolumn{2}{|l|}{$\begin{array}{l}\text { Authors: } \\
\text { He Ding }{ }^{1} \text { (1) } \\
\text { Enhai Yu }{ }^{1} \text { (1) } \\
\text { Yanbin Li } \text { Li }^{1} \mathbb{0}\end{array}$} \\
\hline \multicolumn{2}{|c|}{$\begin{array}{l}\text { Affiliations: } \\
{ }^{1} \text { Department of Economics } \\
\text { and Management, Faculty of } \\
\text { Business Management, } \\
\text { North China Electric Power } \\
\text { University, Beijing, China }\end{array}$} \\
\hline \multicolumn{2}{|c|}{$\begin{array}{l}\text { Corresponding author: } \\
\text { Enhai Yu, } \\
\text { yenh@ncepu.edu.cn }\end{array}$} \\
\hline \multicolumn{2}{|c|}{$\begin{array}{l}\text { Dates: } \\
\text { Received: } 02 \text { Nov. } 2019 \\
\text { Accepted: } 26 \text { Oct. } 2020 \\
\text { Published: } 17 \text { Dec. } 2020\end{array}$} \\
\hline \multicolumn{2}{|c|}{$\begin{array}{l}\text { How to cite this article: } \\
\text { Ding, H., Yu, E., \& Li, Y. } \\
\text { (2020). Strengths-based } \\
\text { leadership and its impact } \\
\text { on task performance: A } \\
\text { preliminary study. South } \\
\text { African Journal of Business } \\
\text { Management, 51(1), a1832. } \\
\text { https://doi.org/10.4102/ } \\
\text { sajbm.v51i1.1832 }\end{array}$} \\
\hline \multicolumn{2}{|c|}{$\begin{array}{l}\text { Copyright: } \\
\text { (c) 2020. The Authors } \\
\text { Licensee: AOSIS. This } \\
\text { is licensed under the } \\
\text { Creative Commons } \\
\text { Attribution License. }\end{array}$} \\
\hline \multicolumn{2}{|l|}{ Read online: } \\
\hline 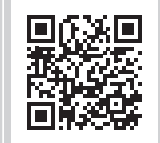 & $\begin{array}{l}\text { Scan this QR } \\
\text { code with your } \\
\text { smart phone or } \\
\text { mobile device } \\
\text { to read online. }\end{array}$ \\
\hline
\end{tabular}

Purpose: The current article aims to develop and validate the strengths-based leadership (SBL) scale and to explore the association of SBL with task performance and the roles of work-related well-being (WWB) and work pressure in the relationship.

Design/methodology/approach: The exploratory factor and the confirmatory factor analyses were applied to assess the validity and reliability of the SBL scale. A total of 342 employees (female $=54.1 \%$; mean age $=30.37$ years, standard deviation $[S D]=5.90$ years $)$ from various Chinese enterprises were used to test the association of SBL with task performance.

Findings/results: The results revealed that the two-dimensional SBL scale shows appropriate validity and reliability, and SBL is positively correlated with task performance. In addition, we also found that WWB acts as a mediator in the SBL-task performance linkage, and work pressure can enhance the direct association of SBL with WWB and the indirect association of SBL with task performance via WWB.

Practical implication: Our findings have some significant managerial implications in promoting employees' task performance and research on SBL provides a new insight into leadership development.

Originality/value: This article provides a useful tool to measure the SBL construct and is the first to empirically examine the effects of SBL.

Keywords: strengths-based leadership; task performance; work-related well-being; work pressure; preliminary study.

\section{Introduction}

In recent years, the strengths-based approach has triggered a great many scholars' interests (Brunetto et al., 2020; Peláez, Coo, \& Salanova, 2019). Numerous studies have revealed that the strengths-based approach is not only positively associated with individuals' satisfaction with life (Duan et al., 2014), calling (Harzer \& Ruch, 2016), work-related wellbeing (WWB) (Meyers \& Van Woerkom, 2017) and performance (Van Woerkom et al., 2016a) but also plays an important role in lowering absenteeism (Van Woerkom, Bakker, \& Nishii, 2016b) and depression (Gander et al., 2013). Given that, scholars have begun to apply the strengths-based approach to the field of human resource management. For example, the strengths-based psychological climate was developed to elucidate how organisations improve employees' job performance by appreciating, identifying, developing and leveraging employees' strengths (Van Woerkom \& Meyers, 2015).

Leadership is a potentially crucial influencing factor of employees' performance (Chen et al., 2018; Stollberger et al., 2019) and researchers have attempted to integrate the strengths-based approach into leadership theory (Linley, Govindji, \& West, 2007). The Gallup organisation's investigation found that the effective leaders pay more attention to their own strengths and subordinates' strengths (Burkus, 2011; Rath \& Conchie, 2008). Importantly, strengths-based leaders can effectively respond to the complex business environment such as current COVID-19 by utilising each employee's strengths (Burkus, 2011; Ruethaivanich \& Scott, 2017). To date, strengths-based leadership (SBL) has been broadly used in the field of leadership improvement (Mackie, 2016; Peláez, Salanova, \& Martínez, 2020). Prior research has suggested SBL to positively relate to followers' optimism, engagement, creativity and performance (Burkus, 2011; Welch et al., 2014). Yet, no previous empirical literature has confirmed the effects of SBL on employees and organisational outcomes (Lin \& Ding, 2018). Thus, the current article aims to bridge this gap by developing and validating the SBL scale and empirically investigating the SBL-task performance linkage. 
In addition, this study also examines the mediational role of WWB and the moderating role of work pressure in the linkage. According to happy-productive theory, happy employees are more inclined to achieve higher levels of productivity (Lyubomirsky, King, \& Diener, 2005). When happiness is conceptualised as WWB and productivity is conceptualised as task performance, WWB induced by SBL might lead to enhanced task performance. Previous literature has found that strengths-based intervention could lead to increased employees' WWB (Meyers \& Van Woerkom, 2017), and employees' well-being has been also confirmed to be associated with task performance (Hosie, Willemyns, \& Sevastos, 2012). Accordingly, it is feasible to postulate that WWB plays a mediating role in the SBL-task performance linkage. Furthermore, job demands-resources (JD-R) theory points out that job resources are more useful, especially when the level of job demands is high (Bakker \& Demerouti, 2017). Given that work pressure is an important form of job demands (Schaufeli \& Taris, 2014) and SBL can be considered as a crucial job resource, we posit work pressure to moderate the direct association of SBL with WWB and the indirect association of SBL with task performance through WWB. In sum, the present article aims to examine a moderated mediation model regarding SBL, WWB, work pressure and task performance. The current study contributes to advancing the SBL theory and research.

\section{Theory and hypotheses development Definitions of strength}

To better understand the concept of SBL, it is essential to introduce what is strength. Different scholars showed differentiated understandings of individual strengths (Buckingham \& Clifton, 2001; Clifton \& Harter, 2003). According to the existing literature, strength has been defined in five ways (Lin \& Ding, 2018). Firstly, Buckingham and Clifton (2001) suggest that strengths are comprised of talents, knowledge and skills. Strengths can enable individuals to achieve sustained excellent performance. Talent refers to the thought, feeling or behaviour patterns that are inherently recurring; knowledge consists of learned facts and experiences; and skills are the basic ability to accomplish a specific step in a task (Miglianico et al., 2020).

Secondly, Peterson and Seligman (2004) defined strengths as trait-like characteristics existing in the individual's thinking, feelings and behaviours. When individuals' strengths are used, individuals' goals will be more likely to be reached. They also believed that strengths are both stable and malleable. More importantly, the function of strengths is contingent on individual characteristics such as personality and other strengths' presentation (Peterson \& Seligman, 2004).

Thirdly, Linley and Harrington (2006) defined strengths from the perspective of the process and outcome of strengths is used as a natural ability to behave, think, or feel. Each of the above definitions of strengths has one-sidedness. These three views cannot comprehensively cover all strengths of individuals whilst giving individuals sufficient freedom in defining their strengths. To overcome these limitations as much as possible, Wood et al. (2011) redefined strengths as personal characteristics, which enable individuals to attain excellent performance. It is worth noting that the definition of Wood et al. (2011) does not include individual outer strengths, which might originate from external resources, relations and opportunities (Gottlieb, 2014). Subsequently, Niemiec (2012) pointed out that individuals' strengths should consist of inner strengths (e.g. character strengths) and outer strengths (e.g. valuable outer resources). Based on the above discussion, the present article defines strength as individual inner characteristics and external resources or conditions in a specific situation which can help employees to achieve near-perfect performance, growth and development. In essence, strength is determined by context, that is, strength in a situation might not be strength in other situations (Biswas-Diener, Kashdan, \& Minhas, 2011).

\section{Connotation of strengths-based leadership}

Strengths-based leadership is a specific form of positive leadership style (Burkus, 2011; Linley et al., 2007; Welch et al., 2014). Strengths-based leadership is lodged in the assumption that strengths provide individuals with the greatest likelihood of development (Buckingham \& Clifton, 2001; Burkus, 2011). Strengths-based leaders concentrate on the identification, deployment and development of their own and subordinates' strengths, which in turn improve organisational effectiveness (Burkus, 2011; Ward, 2018). It is noteworthy that leaders focusing on strengths also care about how to avoid the negative effects of deficits (Clifton \& Harter, 2003). Aguinis, Gottfredson and Joo (2012, p. 108) pointed out that leaders can avoid the negative effects of employees' deficits by delivering positive feedback.

Strengths-based leadership is different from the leadermember exchange (LMX), authentic leadership, humble leadership and transformational leadership. With respect to LMX, it highlights the different subordinate roles (in-group and out-group) (Dienesch \& Liden, 1986). Strengths-based leaders do not differentiate subordinate roles but treat all subordinates equally. In general, SBL can significantly improve the quality of LMX. As for authentic leadership, it stresses that leaders know and authentically accept their strengths and weaknesses (Walumbwa et al., 2008), but it does not emphasise the investment in strengths' development and use. Humble leaders can proactively acknowledge personal limitations and appreciate subordinates' strengths and contributions (Owens \& Hekman, 2012), whereas they do not deliberately invest more energy and resources in strengths identification, development and deployment. Moreover, humble leadership belongs to the bottom-up leadership style, emphasising the role of subordinates in the leadership process (Chen et al., 2018; Owens \& Hekman, 2012). Contrary to humble leadership, SBL emphasises the role of leaders in facilitating subordinates' strengths 
use by influencing subordinates. Furthermore, although Bakker and Van Woerkom (2018) demonstrate that transformational leaders may stimulate subordinates to use their strengths by individual consideration, transformational leaders aim to improve employees' performance primarily by crafting employees' attitudes and values (Rafferty \& Griffin, 2004). This signifies that transformational leaders and strengths-based leaders adopt different ways to achieve organisational success.

Based on the above discussion, we define SBL as a positive leadership style that aims to foster positive, subjective experience by promoting the identification, development and deployment of supervisors' own and subordinates' strengths, thus helping organisations achieve sustained competitive advantage.

\section{Strengths-based leadership and task performance}

The current study posits that SBL is positively related to task performance. Firstly, strengths-based leaders are more likely to recognise subordinates' strengths and then place subordinates in positions congruent to their strengths (Key-Roberts, 2014), which ultimately improves the subordinates' task performance. Secondly, leaders who focus on strengths tend to make more efforts to identify, develop and leverage their own strengths (Rath \& Conchie, 2008). These behaviours leaders execute may become a role model. According to social learning theory (Fox, Nobles, \& Akers, 2011), when subordinates noticed several positive behaviours leaders performed and such behaviors could lead to valuable outcomes; subordinates would tend to imitate these behaviours. According to this logic, SBL may enhance subordinates' strengths use behavior that, in turn facilitates task performance. Thus, we can obtain the following hypothesis:

H1: Strengths-based leadership is positively correlated with task performance.

\section{Strengths-based leadership and work-related well-being}

Schaufeli and Salanova (2010) suggested that purposive workplace interventions can influence employees' WWB. As noted earlier, strengths-based leaders can proactively take actions to help subordinates to identify, develop and use their strengths. For example, strengths-based leaders motivate subordinates to recognise their strengths by strengths-based performance feedback (Aguinis et al., 2012); leaders can provide subordinates with autonomy support to facilitate them to work on their strengths (Kong \& Ho, 2016). These intervention behaviours beneficial to strengths use are able to boost WWB. A recent field experiment study has found that stimulating individuals to develop and use their strengths could facilitate WWB (Meyers \& Van Woerkom, 2017). Besides, Burkus (2011) also noted that SBL appears to be an important antecedent to employees' well-being. As such, we postulate:

H2: Strengths-based leadership is positively correlated with WWB.

\section{The mediating role of work-related well-being}

Broaden-and-build theory suggests that positive emotions such as WWB can 'broaden people's momentary thoughtaction repertoires and build their enduring personal resources' (Fredrickson, 2001, p. 219) that, in turn, lead to improved task performance (Ouweneel, Schaufeli, \& Le Blanc, 2013). This argument has been confirmed by a substantial body of empirical research. For instance, Wright, Cropanzano and Bonett (2007) found that well-being was related to supervisor performance ratings. Such finding to a certain extent provides initial support for the WWB-task performance linkage. As predicted earlier, SBL is positively related to WWB. Based on the above discussion, it is possible to expect that WWB acts as a mediator in the SBL-task performance linkage. Hence, we assume:

H3: Work-related well-being mediates the association of SBL with task performance.

\section{The moderating role of work pressure}

Job demands-resources theory demonstrates that job resources will be more useful when the level of job demands is high (Bakker \& Demerouti, 2017; Hobfoll, 2001). Research conducted on Finnish teachers and dentists revealed that when job demands are high, the relationships between job resources and work engagement are stronger (Bakker \& Demerouti, 2017). Because SBL as a key driving force of subordinates' strengths use can be viewed as a vital job resource and work engagement is regarded as a form of WWB (Meyers \& Van Woerkom, 2016), work pressure as a hindrance to work demand (Bakker \& Sanz-Vergel, 2013) may act as a moderator between SBL and WWB. Specifically, when work pressure is high, the relationship between SBL and WWB will be more positive. In contrast, the relationship between SBL and WWB will be weaker for employees low in work pressure. In sum, we obtain the following hypothesis:

H4: Work pressure will boost the association of SBL with WWB, such that the relationship is stronger for employees who have a high level of work pressure than those who have a low level of work pressure.

Based on the above discussion, we further postulate:

H5: Work pressure will boost the indirect association of SBL with task performance via WWB, such that the indirect relationship is stronger for employees with higher work pressure than those with low work pressure.

\section{Methods}

\section{Sample and procedure}

The current study adopted a cross-sectional research design. A self-report online questionnaire in Chinese was used to collect data. The convenience sampling was applied to recruit participants from diverse organisations in China. Participants volunteered to participate in this research and were informed that they have the freedom to stop their participation at any time. After receiving consent 
from participants, we distributed 520 questionnaires and received 342 valid responses. Of the 342 respondents, $54.1 \%$ were male and $78.0 \%$ had graduated from 4 -years universities. Regarding organisational tenure, $18.2 \%$ had worked 3 years and below, and $66.1 \%$ had worked between 3 and 10 years. Besides, the respondents' average age was 30.4 years.

\section{Instruments}

All items of the main variables were evaluated on a five-point Likert scale ranging from 1 = strongly disagree to $5=$ strongly agree unless otherwise noted. Before applying English-based scales including task performance, WWB, work pressure, LMX, humble leadership and transformational leadership to Chinese respondents, we conducted translation and back-translation procedure for these scales (Brislin, 1970). Chinese-based scales of SBL and authentic leadership were used in the current study.

\section{Strengths-based leadership}

Because no existing scale can be applied to measure the SBL construct, we tried to develop an SBL scale. Based on the definition of SBL and previous research (Van Woerkom et al., 2016a; Van Woerkom \& Meyers, 2015), we put forward the initial eight items. Five items were used to measure subordinate's SBL (Ding \& Yu, 2020) and three items were used to measure the supervisor's own SBL. A sample item was 'My supervisor discusses with me how I can improve my strengths'.

Two independent samples that were from two other surveys targeted to different participants were utilised to examine the reliability and validity of the SBL scale. The exploratory factor analysis (EFA) was conducted on data from 112 employees working in diverse organisations in China. Also, we performed the confirmatory factor analysis (CFA) on other data sets from 237 respondents. The results showed that the two-dimensional SBL scale with eight-item reports appropriate validity and reliability. Further, discriminant validity also demonstrated that the SBL construct is different from authentic leadership, humble leadership, transformational leadership and LMX. More detailed results were presented in the 'Data analysis and results' section.

\section{Task performance}

We used a five-item task performance scale used by Williams and Anderson (1991) to measure task performance. A sample item was 'I can adequately complete assigned duties'. The Cronbach's a for the scale was 0.97 .

\section{Work-related well-being}

This was rated using a six-item scale developed by Zheng et al. (2015). A sample item was 'I find real enjoyment in my work'. The Cronbach's a for the scale was 0.92 .

\section{Work pressure}

Work pressure was assessed by adopting three-item scale from the subjective stress scale developed by Motowidlo, Packard and Manning (1986). A sample item was 'My job is extremely stressful'. The Cronbach's a for the scale was 0.87 .

\section{Control variables}

Previous studies have demonstrated that gender, age, education and organisational tenure are associated with task performance (Kamdar \& Van Dyne, 2007). Therefore, the four variables were considered as control variables.

\section{Additional variables}

To verify the uniqueness of SBL construct, we needed to conduct the discriminant validity test between SBL, LMX, authentic leadership, humble leadership and transformational leadership. Leader-member exchange was rated with a seven-item scale developed by Scandura and Graen (1984). An example item was 'My supervisor recognizes my potential'. The Cronbach's a for the scale in the current article was 0.90. Authentic leadership was rated using a 14-item scale developed by Neider and Schriesheim (2011). A sample item was 'My supervisor asks for ideas that challenge his/her beliefs'. The Cronbach's a for the scale in the current article was 0.97 . We measured humble leadership with a 14-item scale developed by Chen, Zhang and Chen (2017). A sample item was 'My supervisor can adopt reasonable suggestions of subordinates'. The Cronbach's a for the scale in the current article was 0.98. We adopted eight items from transformational leadership scale developed by Zhang et al. (2015) to measure transformational leadership. A sample item was 'My supervisor has stimulated me to rethink the way I do things'. The Cronbach's a for the scale in the current article was 0.94 .

\section{Data analysis and results Scale development}

Two independent data sets were used to validate the SBL scale. Exploratory factor analysis was conducted on a sample of 112 Chinese employees working in various organisations in China. Amongst them, 53.6\% were male and $78.6 \%$ had graduated from 4-years universities. For organisational tenure, $19.6 \%$ had worked 3 years and below, and $63.4 \%$ had worked between 3 and 10 years. Besides, the respondents' average age was 30.25 years. The Kaiser-Meyer-Olkin (KMO) index was 0.80, demonstrating that the sample is suitable for factor analysis. Also, Bartlett's test of sphericity was found to be significant $(p<0.001)$, indicating that the item correlation matrix is not an identity matrix, and the sample is appropriate for factor analysis (Tsai et al., 2014). Exploratory factor analysis resulted in two factors (subordinate-focused SBL and supervisor-focused SBL) with eigenvalues above 1, explaining $70.05 \%$ of the total variance in SBL. In terms of the explained variance, the first factor explained $37.84 \%$ of the variance, and the 
second factor explained $32.21 \%$ of the variance. Table 1 presented a more detailed description of the results of EFA.

Subsequently, CFA was conducted on the eight-item SBL scale with other datasets with 237 employees from Chinese organisations in AMOS 21. Of 237 employees, $52.7 \%$ were male and $93.7 \%$ had graduated from 4 -years universities. As for organisational tenure, 9.3\% had worked in the current organisation for 3 years and below, and $36.7 \%$ between 3 and 10 years, $54.0 \%$ beyond 10 years. In addition, the average age of 237 employees was 35.18 years. Results of CFA showed that fit indices of two-factor model $\left(\chi^{2} /\right.$ degrees of freedom $[d f]=3.09$, comparative fit index $[\mathrm{CFI}]=0.97$, Tucker Lewis index $[\mathrm{TLI}]=0.96$, standardized root mean square residual [SRMR] $=0.05)$ are adequate and better than single-factor model $\left(\chi^{2} / d f=\right.$ $11.29, \mathrm{CFI}=0.85, \mathrm{TLI}=0.79, \mathrm{SRMR}=0.07)$. In addition, the Cronbach's a reliability of the scale in this dataset was 0.92. Discriminant validity was also conducted on the sample of 237 employees. Result demonstrated that the five-factor measurement model (SBL, authentic leadership, humble leadership, transformational leadership and LMX) reports a good fit $\left(\chi^{2} / d f=2.93, \mathrm{CFI}=0.96, \mathrm{TLI}=0.95\right.$, SRMR $=0.04)$. In sum, based on the above analyses, we can conclude that the SBL scale has good validity and reliability. The Cronbach's a of the SBL scale in a sample of 342 respondents was 0.93 .

\section{Descriptive statistics and correlations}

Means, standard deviations and correlations between variables were displayed in Table 2 . Amongst main variables, SBL positively correlates with task performance $(r=0.35$, $p<0.01)$ and WWB $(r=0.49, p<0.01)$ and negatively correlates with work pressure $(r=-0.30, p<0.01)$; task performance positively correlates with WWB $(r=0.41, p<0.01)$ and negatively correlates with work pressure $(r=-0.30, p<0.01)$. In addition, WWB is negatively linked with work pressure $(r=-0.31, p<0.01)$.

TABLE 1: Exploratory factor analysis of the strengths-based leadership scale.

\begin{tabular}{lcc}
\hline SBL & \multicolumn{2}{c}{ Loadings } \\
\cline { 2 - 3 } & Factor 1 & Factor 2 \\
\hline $\begin{array}{l}\text { My supervisor provides me with the } \\
\text { opportunity to let me know what I am good at }\end{array}$ & $\mathbf{0 . 7 7}$ & 0.26 \\
$\begin{array}{l}\text { My supervisor encourages me to further } \\
\text { develop my potential }\end{array}$ & $\mathbf{0 . 7 6}$ & 0.28 \\
$\begin{array}{l}\text { My supervisor is good at using my strengths } \\
\begin{array}{l}\text { My supervisor gives me more autonomy to use } \\
\text { my strengths at work }\end{array}\end{array}$ & $\mathbf{0 . 7 6}$ & 0.75 \\
$\begin{array}{l}\text { My supervisor discusses with me how I can } \\
\text { improve my strengths }\end{array}$ & $\mathbf{0 . 7 5}$ & 0.19 \\
$\begin{array}{l}\text { My supervisor knows his or her talents } \\
\begin{array}{l}\text { My supervisor makes the most of his or her } \\
\text { strong points at work }\end{array}\end{array}$ & 0.20 & 0.08 \\
$\begin{array}{l}\text { My supervisor engages more his or her time } \\
\text { and energy to develop his or her strengths }\end{array}$ & 0.26 & $\mathbf{0 . 9 1}$ \\
\hline
\end{tabular}
and energy to develop his or her strengths

Note: The bold values do not exhibit significance in EFA. Factor 1 is named as subordinate's strengths-based leadership; Factor 2 is named as supervisor's own strengths-based leadership. Given that this scale was developed in Chinese, we conducted translation and back-translation procedure to obtain the English-based scale. Specifically, a professional translator translated Chinese scale into English-based scale and then two associate professors translated the English-based scale into Chinese scale to ensure items equivalence. SBL, strengths-based leadership.

\section{Hypotheses testing}

The bootstrapping procedure was employed to examine our predictions (Hayes, 2009). Bias-corrected confidence intervals (CI) with 5000 bootstrapping re-samples were used to determine the significance of the mediation and moderation effects (Hayes, 2009). The reason of why we adopt the bootstrapping procedure to test hypotheses of this study was that it had been confirmed as a quite effective method for examining mediating and moderating effects (Ahmad \& Gao, 2018; Zhao, Lynch, \& Chen, 2010).

Analytical results were presented in Table 3. Based on Model 2 and Model 1 in Table 3, we can conclude that SBL positively correlates with task performance $(\beta=0.30$, $p<0.001)$ and WWB $(\beta=0.40, p<0.001)$, supporting Hypothesis 1 and Hypothesis 2. Hypothesis 3 postulated that WWB mediates the SBL-task performance linkage. The indirect association of SBL with task performance through WWB was significant (WWB: $\beta=0.32, p<0.001$; SBL: $\beta=0.18, p<0.001)$, which was supportive of Hypothesis 3.

Hypothesis 4 assumed that work pressure positively moderated the relationship between SBL and WWB. Prior to testing Hypothesis 4, SBL and work pressures were standardised. The result in Table 3 (Model 4) indicated that the interaction term between SBL and work pressure was significant $(\beta=0.12, p<0.001,95 \% \mathrm{CI}$ : [0.06, 0.19]), demonstrating that work pressure enhances the positive impact of SBL on WWB. In order to present the moderating effect of work pressure more clearly, the moderation effect was depicted in Figure 1. As revealed in Figure 1, for employees with higher work pressure, the relationship between SBL and WWB was stronger. Thus, Hypothesis 4 was supported.

Hypothesis 5 assumed that work pressure moderated the indirect relationship of SBL with task performance through WWB. We examined the moderated mediation model by following Hayes (2013) approach. Results indicated that the moderated mediation index was 0.04, CI: [0.01, 0.08]. In addition, as shown in Table 4, the relationship of SBL with task performance through WWB was stronger for employees high in work pressure (effect $=0.42, p<0.001$, 95\% CI: [0.33, 0.50]) than for employees low in work pressure (effect $=0.17, p<0.001,95 \% \mathrm{CI}$ : [0.06, 0.28]). Hence, $\mathrm{H} 5$ also was confirmed.

TABLE 2: Descriptive statistics and correlation between variables.

\begin{tabular}{lccccc}
\hline Variable & $\boldsymbol{M}$ & SD & $\mathbf{1}$ & $\mathbf{2}$ & $\mathbf{3}$ \\
\hline SBL & 3.56 & 0.94 & - & - & - \\
TP & 3.96 & 0.77 & $0.35^{* *}$ & - & - \\
WWB & 3.51 & 0.82 & $0.49^{* *}$ & $0.41^{* *}$ & - \\
WP & 2.97 & 1.01 & $-0.30^{* *}$ & $-0.23^{* *}$ & $-0.31^{* *}$ \\
\hline
\end{tabular}

SBL, strengths-based leadership; TP, task performance; WWB, work-related well-being WP, work pressure, $M$, mean; SD, standard deviation.

$* *, p<0.01$ 
TABLE 3: Results for mediation and moderation analyses.

\begin{tabular}{|c|c|c|c|c|c|c|c|c|}
\hline \multirow[t]{3}{*}{ Variable } & \multicolumn{4}{|c|}{ WWB } & \multicolumn{4}{|c|}{ Task performance } \\
\hline & \multicolumn{2}{|c|}{ Model 1} & \multicolumn{2}{|c|}{ Model 4} & \multicolumn{2}{|c|}{ Model 2} & \multicolumn{2}{|c|}{ Model 3} \\
\hline & $B$ & $t$ & $B$ & $t$ & $\beta$ & $t$ & $\beta$ & $t$ \\
\hline Gender & $-0.42 * * *$ & -5.27 & $-0.41 * * *$ & -5.05 & -0.14 & -1.65 & 0.00 & 0.00 \\
\hline Age & $-0.02 *$ & -2.35 & -0.01 & -1.05 & $0.03 * *$ & 3.03 & $0.03 * * *$ & 3.93 \\
\hline Education & -0.07 & -1.40 & $-0.12 *$ & -2.24 & -0.01 & -0.24 & 0.01 & 0.22 \\
\hline Tenure in organisation & 0.03 & 0.87 & 0.00 & 0.00 & $-0.11 * *$ & -3.39 & $-0.12 * * *$ & -3.84 \\
\hline WWB & - & - & - & - & - & - & $0.32 * * *$ & 6.05 \\
\hline Work pressure & - & - & $-0.10^{*}$ & -2.46 & - & - & - & - \\
\hline $\mathrm{SBL} \times$ work pressure & - & - & $0.12 * * *$ & 3.78 & - & - & - & - \\
\hline$F$-value & $28.23 * * *$ & - & $24.20 * * *$ & - & $13.35 * * *$ & - & $18.39 * * *$ & - \\
\hline$R$ & 0.54 & - & 0.58 & - & 0.41 & - & 0.50 & - \\
\hline$R^{2}$ & 0.30 & - & 0.34 & - & 0.17 & - & 0.25 & - \\
\hline
\end{tabular}

SBL, strengths-based leadership; WWB, work-related well-being.

$*, p<0.05 ; * *, p<0.01 ; * * *, p<0.001$

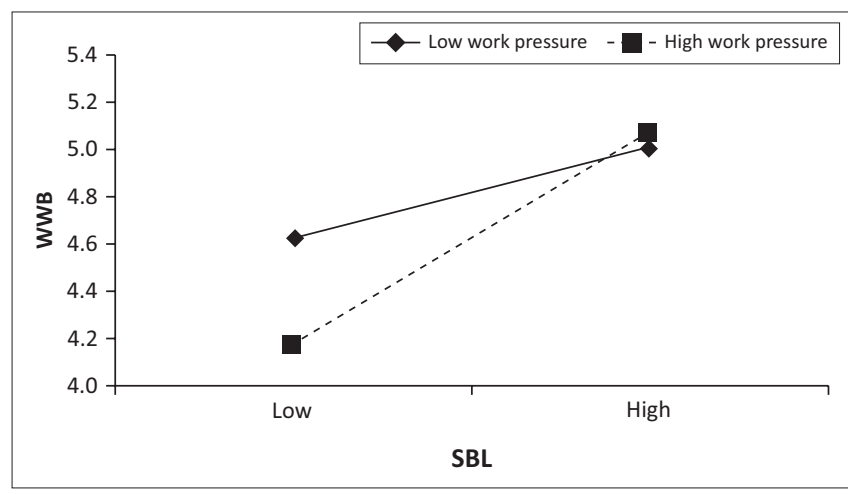

SBL, strengths-based leadership; WWB, work-related well-being.

FIGURE 1: Interaction plot of strengths-based leadership and work pressure on work-related well-being.

TABLE 4: Conditional indirect effects of strengths-based leadership on task performance via work-related well-being, at levels of work pressure.

\begin{tabular}{lcccc}
\hline Variable & Effect & SE & 95\% LLCI & 95\% ULCI \\
\hline Low WP, SBL-WWL-TP & 0.17 & 0.06 & 0.06 & 0.28 \\
Medium WP, SBL-WWL-TP & 0.29 & 0.04 & 0.22 & 0.37 \\
High WP, SBL-WWL-TP & 0.42 & 0.04 & 0.33 & 0.50 \\
\hline
\end{tabular}

LLCI, lower level of confidence intervals; SBL, strengths-based leadership; SE, standard error; WWL, work-related well-being; WP, work pressure; TP, task performance; ULCI, upper level of confidence intervals.

\section{Discussion}

The current article developed a scale to measure the SBL construct and investigated the SBL-task performance relationship and the mediating effect of WWB and the moderating effect of work pressure on this relationship. Results of this article suggested that the two-dimensional SBL scale with eight-item (five items for subordinate-focused SBL and three items for supervisor-focused SBL) reported good validity and reliability. Furthermore, this study found a significant positive relationship between SBL and task performance and confirmed the partially mediational effect of WWB and the positively moderating effect of work pressure on the relationship between SBL, WWB and task performance.

\section{Theoretical implications}

The current study advances the SBL theory and research in four ways. Firstly, developing the SBL scale showing appropriate reliability and validity provides a useful tool for future empirical research on SBL. Extant literature has demonstrated the importance of SBL on employee outcomes and organisational effectiveness, but there is little empirical evidence confirming the positive effects of SBL. One potential reason is the lack of useful scale to evaluate SBL. Our study advances the SBL research by developing and validating a two-dimensional eight-item SBL scale. It is important to note that the discriminant validity test indicates that the SBL construct is distinct from related constructs including authentic leadership, humble leadership, transformational leadership and LMX. This offers robust evidence for the uniqueness of the SBL construct.

Secondly, the present article is the first to empirically investigate the SBL-task performance linkage. Research regarding the role of strengths in elevating employee performance has become a hot topic amongst researchers in the area of organisational psychology. Some researchers have tried to confirm the relationship between strengths and performance from a different perspective. For instance, Van Woerkom and Meyers (2015) revealed the positive effect of strengths-based psychological climate on performance. Even though the existing literature pointed out the importance of SBL in eliciting employee positive affect, work engagement, and productivity, to our knowledge, no previous research was found to explore the SBL-task performance relationship. Thus, this study provides important evidence for the positive association of SBL with task performance.

Thirdly, by investigating the mediational effect of WWB on the SBL-task performance link, the current study contributes to a better understanding how SBL translates into task performance. In line with previous research (Meyers \& Van Woerkom, 2017), our findings suggest that helping employees recognising, developing and leveraging their strengths can elicit their WWB. More importantly, increased WWB resulting from SBL can further lead to enhanced task performance as happy employees tend to perform their tasks better (Lyubomirsky et al., 2005). 
Fourthly, the current study deepens our understanding of the boundary condition of the associations between SBL, WWB and task performance by investigating the moderating effect of work pressure. In line with JD-R theory (Bakker \& Demerouti, 2017), when job demand, this study conceptualises job demand as work pressure, is high, job resource conceptualised as SBL will become more effective in predicting valuable outcomes. Specifically, the effect of SBL is more positive for employees with a high level of work pressure than for employees with a low level of work pressure. Although the positive effects of SBL have been recognised in previous studies, there is no evidence exploring the boundary conditions of these effects. Hence, the current study suggesting that the effects of SBL vary as a function of work pressure helps us understand when SBL is more useful.

\section{Managerial suggestions}

The current study provides some promising managerial suggestions to enhance employees' task performance. Firstly, based on the positive association between SBL and task performance, we propose that organisations should promote leaders who have the ability to identify, develop and use their own strengths and subordinates' strengths. To this end, organisations should first identify strengthsbased leaders by scientific tools such as StrengthsFinder 2.0 (Rath \& Conchie, 2008) or SBL scale developed by the current study. In addition, organisations can also improve the current leaders' abilities to focus on strengths by strengths intervention training. Secondly, the mediational effect of WWB on the relationship between SBL and task performance signifies that eliciting employees' WWB is an important path to facilitate employees' task performance. According to prior research, an organisation could increase employees' WWB by implementing effective strengths intervention (Meyers \& Van Woerkom, 2017) and high-performance work system (Mihail \& Kloutsiniotis, 2016). Thirdly, given the positively moderating effect of work pressure on the effects of SBL, strengths-based leaders should pay more attention to subordinates with higher levels of work pressure as subordinates who experience higher work pressure are likely to benefit more from SBL.

\section{Limitations and directions for future research}

Whilst the current article has some theoretical and managerial implications, there still exists a number of limitations. Firstly, although the new SBL scale explained $70.05 \%$ of SBL variance and had adequate reliability and validity, we did not follow a systematic process of scale development. Future research should attempt to adopt a more systematic process of scale development to develop a better SBL scale. Moreover, the SBL scale was developed in the Chinese context, little is known about whether the scale is suitable for other cultural contexts. It is necessary to test cross-cultural applicability of the SBL scale. Secondly, data used in the current study were collected from a single source at a single time point, which limited causal relations of this article. Moreover, potential common-method bias because of a cross-sectional research design may lower the validity of the results of this article. Future research should try to gather data from different sources or conduct a longitudinal study to confirm the causal relations. Thirdly, in the current study, we mainly focused on subordinate's perception of SBL because such perception may be closely linked with task performance and WWB. In the future, research on the effects of SBL at a higher level is a promising direction. Fourthly, task performance was evaluated by the self-report scale in the current study. Future research should attempt to rate task performance by peer-report scale or objective indices to replicate our findings. Finally, the current study did not consider the job level as a control variable. Because employees on different job levels might have different perceptions of the same leader, in the future research, it is important to view job level as a control variable to lower the influence of job level on the effectiveness of our research findings.

\section{Acknowledgements}

The authors are grateful to the employees who participated in this study.

\section{Competing interests}

The authors have declared that no competing interests exist.

\section{Authors' contributions}

All authors contributed equally to this work.

\section{Ethical consideration}

This article followed all ethical standards for a research.

\section{Funding information}

This work was supported by the Fundamental Research Funds for the Central Universities (2020MS046).

\section{Data availability statement}

The data that support the findings of this study are available from H.D. upon reasonable request.

\section{Disclaimer}

The views and opinions expressed in this article are those of the authors and do not necessarily reflect the official policy or position of any affiliated agency of the authors.

\section{References}

Aguinis, H., Gottfredson, R.K., \& Joo, H. (2012). Delivering effective performance feedback: The strengths-based approach. Business Horizons, 55(2), 105-111. https://doi.org/10.1016/j.bushor.2011.10.004

Ahmad, I., \& Gao, Y. (2018). Ethical leadership and work engagement: The roles of psychological empowerment and power distance orientation. Management Decision, 56(9), 1991-2005. https://doi.org/10.1108/MD-02-2017-0107 
Bakker, A.B., \& Demerouti, E. (2017). Job demands-resources theory: Taking stock and looking forward. Journal of Occupational Health Psychology, 22(3), 273-285. https://doi.org/10.1037/ocp0000056

Bakker, A.B., \& Sanzvergel, A.I. (2013). Weekly work engagement and flourishing: The role of hindrance and challenge job demands. Journal of Vocational Behavior, 83(3), 397-409. https://doi.org/10.1016/j.jvb.2013.06.008

Bakker, A.B., \& Van Woerkom, M. (2018). Strengths use in organizations: A positive approach of occupational health. Canadian Psychology/Psychologie Canadienne, 59(1), 38-46. https://doi.org/10.1037/cap0000120

Biswas-Diener, R., Kashdan, T.B., \& Minhas, G. (2011). A dynamic approach to psychological strength development and intervention. The Journal of Positive Psychology, 6(2), 106-118. https://doi.org/10.1080/17439760.2010.545429

Brunetto, Y., Dick, T., Xerri, M., \& Cully, A. (2020). Building capacity in the healthcare sector: A strengths-based approach for increasing employees' well-being and organisational resilience. Journal of Management \& Organization, 26(3), 309-323. https://doi.org/10.1017/jmo.2019.53

Brislin, R.W. (1970). Back-translation for cross-cultural research. Journal of CrossCulturalPsychology,1(3),185-216.https://doi.org/10.1177/135910457000100301

Buckingham, M., \& Clifton, D. (2001). Now, discover your strengths. New York, NY: Free Press.

Burkus, D. (2011). Building the strong organization: Exploring the role of organizational design in strengths-based leadership. Journal of Strategic Leadership, 3(1), 54-66.

Chen, Y., Liu, B., Zhang, L., \& Qian, S. (2018). Can leader 'humility' spark employee 'proactivity'? The mediating role of psychological empowerment. Leadership \& Organization Development Journal, 39(3), 326-339. https://doi.org/10.1108/ LODJ-10-2017-030

Chen, Y.H., Zhang, L., \& Chen, L. (2017). The structure and measurement of humble leadership in Chinese cultural context. Journal of Management Science, 30(3), $14-22$

Clifton, D.O., \& Harter, J.K. (2003). Investing in strengths. In K.S. Cameron, J.E. Dutton \& R.E. Quinn (Eds.), Positive organizational scholarship: Foundations of a new discipline (pp. 111-121). San Francisco, CA: Berrett-Kohler.

Dienesch, R.M., \& Liden, R.C. (1986). Leader-member exchange model of leadership: A critique and further development. Academy of Management Review, 11(3) 618-634. https://doi.org/10.2307/258314

Ding, H., \& Yu, E. (2020). Follower strengths-based leadership and follower innovative behavior: The roles of core self-evaluations and psychological well-being. Journa of Work and Organizational Psychology, 36(2), 103-110. https://doi.org/10.5093/ of Work and

Duan, W., Ho S.M. Tang X. Li, T. \& Zhang, $Y$. (2014). Character strength-based intervention to promote satisfaction with life in the Chinese university context. intervention to promote satisfaction with life in the Chinese university context.
Journal of Happiness Studies, 15(6), 1347-1361. https://doi.org/10.1007/s10902Journal of

Fox, K.A., Nobles, M.R., \& Akers, R.L. (2011). Is stalking a learned phenomenon? An empirical test of social learning theory. Journal of Criminal Justice, 39(1), 39-47. https://doi.org/10.1016/j.jcrimjus.2010.10.002

Fredrickson, B.L. (2001). The role of positive emotions in positive psychology: The broaden-and-build theory of positive emotions. American Psychologist, 56(3) 218-226. https://doi.org/10.1037/0003-066X.56.3.218

Gander, F., Proyer, R.T., Ruch, W., \& Wyss, T. (2013). Strength-based positive interventions: Further evidence for their potential in enhancing well-being and alleviating depression. Journal of Happiness Studies, 14(4), 1241-1259. https:// doi.org/10.1007/s10902-012-9380-0

Gottlieb, L.N. (2014). CE: Strengths-based nursing. The American Journal of Nursing 114(8), 24-32. https://doi.org/10.1097/01.NAJ.0000453039.70629.e2

Harzer, C., \& Ruch, W. (2016). Your strengths are calling: Preliminary results of a webbased strengths intervention to increase calling. Journal of Happiness Studies, 17(6), 2237-2256. https://doi.org/10.1007/s10902-015-9692-y

Hayes, A.F. (2009). Beyond Baron and Kenny: Statistical mediation analysis in the new millennium. Communication Monographs, 76(4), 408-420. https://doi. org/10.1080/03637750903310360

Hayes, A.F. (2013). Introduction to mediation, moderation, and conditional process analysis: A regression-based approach. New York, NY: Guilford Press.

Hobfoll, S.E. (2001). The influence of culture, community, and the nested-self in the stress process: Advancing conservation of resources theory. Applied Psychology, 50(3), 337-421. https://doi.org/10.1111/1464-0597.00062

Hosie, P., Willemyns, M., \& Sevastos, P. (2012). The impact of happiness on managers' contextual and task performance. Asia Pacific Journal of Human Resources, 50(3), 268-287. https://doi.org/10.1111/j.1744-7941.2012.00029.x

Kamdar, D., \& Van, D.L. (2007). The joint effects of personality and workplace social exchange relationships in predicting task performance and citizenship performance. Journal of Applied Psychology, 92(5), 1286-1298. https://doi org/10.1037/0021-9010.92.5.1286

Key-Roberts, M. (2014). Strengths-based leadership theory and development of subordinate leaders. Military Review, 94(2), 4-13.

Kong, D.T., \& Ho, V.T. (2016). A self-determination perspective of strengths use at work: Examining its determinant and performance implications. Journal of Positive Psychology, 11(1), 15-25. https://doi.org/10.1080/17439760.2015. 1004555

Lin, X., \& Ding, H. (2018). Applying strengths-based approach in human resource management. Human Resources Development of China, 35(1), 102-111. https:// doi.org/10.16471/j.cnki.11-2822/c.2018.01.010
Linley, P.A., Govindji, R., \& West, M. (2007). Positive psychology approaches to public services leadership: An introduction to strengths-based leadership. The International Journal of Leadership in Public Services, 3(4), 44-55. https://doi. org/10.1108/17479886200700029

Linley, P.A., \& Harrington, S. (2006). Playing to your strengths. Psychologist, 19(2), 86-89.

Lyubomirsky, S., King, L., \& Diener, E. (2005). The benefits of frequent positive affect: Does happiness lead to success? Psychological Bulletin, 131(6), 803-855. https:// doi.org/10.1037/0033-2909.131.6.803

Mackie, D. (2016). Strengths-based leadership coaching in organizations: An evidence-based guide to positive leadership development. London: Kogan Page.

Meyers, M.C., \& Van Woerkom, M. (2017). Effects of a strengths intervention on general and work-related well-being: The mediating role of positive affect. Journal of Happiness Studies, 18(3), 671-689. https://doi.org/10.1007/s10902-016of Happin

Miglianico, M., Dubreuil, P. Miquelon, P., Bakker, A.B., \& Martin-Krumm, C. (2020) Strength use in the workplace: A literature review. Journal of Happiness Studies, 21(2), 737-764. https://doi.org/10.1007/s10902-019-00095-w

Mihail, D.M., \& Kloutsiniotis, P.V. (2016). The effects of high-performance work systems on hospital employees' work-related well-being: Evidence from Greece. European Management Journal, 34(4), 424-438. https://doi.org/10.1016/j. emj.2016.01.005

Motowidlo, S.J., Packard, J.S., \& Manning, M.R. (1986). Occupational stress: Its causes and consequences for job performance. Journal of Applied Psychology, 71(4), 618-629. https://doi.org/10.1037//0021-9010.71.4.618

Neider, L.L., \& Schriesheim, C.A. (2011). The authentic leadership inventory (ALI) Development and empirical tests. The Leadership Quarterly, 22(6), 1146-1164. https://doi.org/10.1016/j.leaqua.2011.09.008

Niemiec, R.M. (2012). Various types of strength [Electronic mailing list message] Retrieved from FRIENDS-OF-PP@lists.apa.org

Ouweneel, E., Schaufeli, W.B., \& Le Blanc, P.M. (2013). Believe, and you will achieve: Changes over time in self-efficacy, engagement, and performance. Applied Psychology: Health and Well-Being, 5(2), 225-247. https://doi.org/10.1111/ aphw.12008

Owens, B.P., \& Hekman, D.R. (2012). Modeling how to grow: An inductive examination of humble leader behaviors, contingencies, and outcomes. Academy of Management Journal, 55(4), 787-818. https://doi.org/10.5465/ amj.2010.0441

Peláez, M.J., Coo, C., \& Salanova, M. (2019). Facilitating work engagement and performance through strengths-based micro-coaching: A controlled trial study. Journal of Happiness Studies, 21, 1265-1284. https://doi.org/10.1007/s10902 019-00127-5

Peláez, Z.M., Salanova, M., \& Martínez, I.M. (2020). Coaching-based leadership intervention program: A controlled trial study. Frontiers in Psychology, 10(1), 3066. https://doi.org/10.3389/fpsyg.2019.03066

Peterson, C., \& Seligman, M.E.P. (2004). Character strengths and virtues: A handbook and classification. Washington, DC: American Psychological Association.

Rafferty, A.E., \& Griffin, M.A. (2004). Dimensions of transformational leadership: Conceptual and empirical extensions. The Leadership Quarterly, 15(3), 329-354. https://doi.org/10.1016/j.leaqua.2004.02.009

Rath, T., \& Conchie, B. (2008). Strengths-based leadership: Great leaders, teams, and why people follow. New York, NY: Gallup Press.

Ruethaivanich, K., \& Scott, A. (2017). The impact of an organization development intervention on the strength-based leadership behaviors of team leaders and team members: A case study in the Health Systems Division of Philips Thailand. ABAC ODI Journal Vision Action Outcome, 4(1), 57-77.

Scandura, T.A., \& Graen, G.B. (1984). Moderating effects of initial leader-member exchange status on the effects of a leadership intervention. Journal of Applied Psychology, 69(3), 428-436. https://doi.org/10.1037/0021-9010.69.3.428

Schaufeli, W.B., \& Salanova, M. (2010). How to improve work engagement? In S. Albrecht (Ed.), The handbook of employee engagement: Perspectives, issues, research and practice (pp. 399-415). Northampton, MA: Edwin Elgar.

Schaufeli, W.B., \& Taris, T.W. (2014). A critical review of the job demands-resources model: Implications for improving work and health. In G. Bauer \& O. Hämmig (Eds.), Bridging occupational organizational \& public health (pp. 43-68). Netherlands: Springer. https://doi.org/10.1007/978-94-007-5640-3-4

Stollberger, J., Las Heras, M., Rofcanin, Y., \& Bosch, M.J. (2019). Serving followers and family? A trickle-down model of how servant leadership shapes employee work performance. Journal of Vocational Behavior, 112(1), 158-171. https://doi. org/10.1016/j.jvb.2019.02.003

Tsai, C.L., Chaichanasakul, A., Zhao, R., Flores, L.Y., \& Lopez, S.J. (2014). Development and validation of the strengths self-efficacy scale (SSES). Journal of Career Assessment, 22(2), 221-232. https://doi.org/10.1177/1069072713493761

Van Woerkom, M., Bakker, A.B., \& Nishii, L.H. (2016b). Accumulative job demands and support for strength use: Fine-tuning the job demands-resources model using conservation of resources theory. Journal of Applied Psychology, 101(1), 141-150. conservation of resources theory. Jou
https://doi.org/10.1037/apl0000033

Van Woerkom, M., \& Meyers, M.C. (2015). My strengths count! Effects of a strengths-based psychological climate on positive affect and job performance. strengths-based psychological climate on positive affect and job performance.
Human Resource Management, 54(1), 81-103. https://doi.org/10.1002/ Human Resol
hrm. 21623 
Van Woerkom, M., Mostert, K., Els, C., Bakker, A.B., De Beer, L., \& Rothmann, Jr. S. (2016a). Strengths use and deficit correction in organizations: Development
and validation of a questionnaire. European Journal of Work and Organizational Psychology, 25(6), 960-975. https://doi.org/10.1080/135943 2X.2016.1193010

Walumbwa, F.O., Avolio, B.J., Gardner, W.L., Wernsing, T.S., \& Peterson, S.J. (2008) Authentic leadership: Development and validation of a theory-based measure. Journal of Management, 34(1), 89-126. https://doi.org/10.1177/0149206 Journal of

Ward, M.E.S. (2018). Strengths-based leadership experiences in child protection teams: A multiple case study. Unpublished doctoral dissertation. Minneapolis, MN: Capella University.

Welch, D., Grossaint, K., Reid, K., \& Walker, C. (2014). Strengths-based leadership development: Insights from expert coaches. Consulting Psychology Journal: Practice and Research, 66(1), 20-37. https://doi.org/10.1037/cpb0000002

Williams, L.J., \& Anderson, S.E. (1991). Job satisfaction and organizational commitmen as predictors of organizational citizenship and in-role behaviors. Journal of Management, 17(3), 601-617. https://doi.org/10.1177/014920639101700305
Wood, A.M, Linley, P.A., Maltby, J., Kashdan, T.B., \& Hurling, R. (2011). Using personal and psychological strengths leads to increases in well-being over time: A longitudinal study and the development of the strengths use questionnaire. Personality and study and the development of the strengths use questionnaire. Personality and
Individual Differences, 50(1), 15-19. https://doi.org/10.1016/j.paid.2010.08.004

Wright, T.A., Cropanzano, R., \& Bonett, D.G. (2007). The moderating role of employee positive well-being on the relation between job satisfaction and job performance. Journal of Occupational Health Psychology, 12(2), 93-104. https://doi. org/10.1037/1076-8998.12.2.93

Zhang, X.A., Li, N., Ullrich, J., \& Van Dick, R. (2015). Getting everyone on board: The effect of differentiated transformational leadership by CEOs on top management team effectiveness and leader-rated firm performance. Journal of Management, 41(7), 1898-1933. https://doi.org/10.1177/0149206312471387

Zhao, X., Lynch, J.G., \& Chen, Q. (2010). Reconsidering Baron and Kenny: Myths and truths about mediation analysis. Journal of Consumer Research, 37(2), 197-206. https://doi.org/10.1086/651257

Zheng, X., Zhu, W., Zhao, H., \& Chi, Z. (2015). Employee well-being in organizations: Theoretical model, scale development, and cross-cultural validation. Journal of Organizational Behavior, 36(5), 621-644. https://doi.org/10.1002/job.199 